\title{
Northern Irish dental leaders look to Westminster for action on oral health
}

\author{
Dental leaders in Northern Ireland are \\ increasingly turning to government at \\ Westminster to address oral health issues, \\ as government in their own province is \\ 'stagnating'.
}

The BDA in Northern Ireland said the province was suffering from a 'policy vacuum' since the devolved administration the Northern Ireland Assembly - effectively collapsed in January 2017 and went into a period of suspension.

Dental problems in the province appear to be growing, said the BDA, which has written to the Westminster government's Northern Ireland Affairs Select Committee to highlight its concerns.

Children in Northern Ireland have the highest number of general anaesthetic extractions in the UK - around 12 people out of 1,000 compared with four per 1,000 in England.

In a letter, BDA Northern Ireland director Tristen Kelso said he wanted to commend the Committee for its recent efforts in holding the Department of Health to account in relation to cancer services in Northern Ireland.

'It is no coincidence that recent positive announcements in relation to access to cancer drugs, and now a cancer strategy have come on foot of a period of effective scrutiny by the committee,' said Kelso.

'Partnering closely with Cancer Focus Northern Ireland around mouth cancer, not least in campaigning for boys in Northern Ireland to be given access to the HPV vaccine as has been confirmed in England, Scotland and Wales, we trust the reality will match the rhetoric for the benefit of citizens here.

'It is not only cancer where the Northern Ireland population have been let down; oral health - which historically has been accepted as being the worst in the UK - has also been functioning in a policy vacuum in the absence of a current oral health strategy'
The most recent oral health strategy dated back to 2007, he added, and had never been formally reviewed while the Northern Ireland Oral Health Improvement Group had been all but disbanded.

'BDA Northern Ireland has been lobbying the Department of Health for a new oral health strategy that can help deliver significant public health improvements - for children - and the elderly population in particular; regrettably, to date our efforts have been met with the same resistance as was the case for so long in relation to a cancer strategy,' he added.

Asked why there had not been a national strategy on oral health in Northern Ireland since 2007, Kelso told the BDJ: 'We don't even have an up to date cancer strategy. Our political situation is complicated and there is no Assembly and no Executive and we appreciate it can be difficult to go ahead and publish new strategies, but it points to a lack of strategic direction and it feels like plugging gaps and firefighting.

'Even when the Assembly and Executive were there, there were campaigns for a new oral health strategy and other strategies within health that fell on deaf ears and were sometimes met with resistance from the Department of Health.

'If you want to make progress on anything, you look at how you are spending your money, you look at your outcomes and you benchmark where you are with everywhere else to adopt things that are working. We haven't even had a review of the 2007 strategy which was meant to have happened within five years.

'I think it's because the Department of Health has so many other issues and is under so much pressure that oral health and dentistry has fallen down its list of priorities.'

Kelso said the BDA felt it had to seek support from Westminster in the absence of a functioning Assembly at home, adding: 'Our frustration

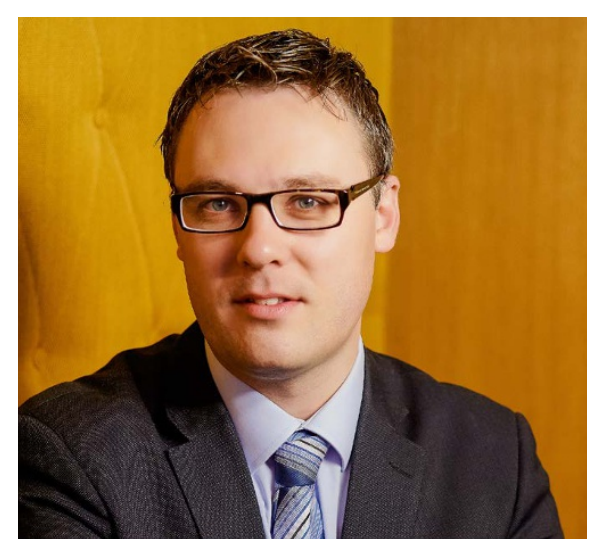

is that civil servants are supposed to perform a different function to politicians and are not meant to be the decision makers, but having no health committee and no Assembly, we can't ask oral questions, we can't probe things and there is a lack of information.

'We have noticed how the Northern Ireland Affairs Select Committee (at Westminster) has upped its game and appreciates there aren't any other forums to scrutinise how public health money is being spent.

'They have undertaken an inquiry [funding priorities in the 2018-19 Budget health inquiry] and we have fed into that with a submission.'

Several BDA committee chairs had a meeting with the Permanent Secretary at the Department of Health scheduled for February 2019 at which he said they had various messages they wanted to covey.

'We want to say that oral health needs to be intrinsic to the main business of health and well-being. Also important is that morale and motivation among the profession is at rock bottom $-70 \%$ of practice owners have low or very low morale here. Over the past eight years, there have been real terms pay cuts within general dental practice.

'We want the Permanent Secretary to accept that the Department has a responsibility to make sure that oral health and the practitioners who underpin it are no longer neglected. We want to get the message across that we want a sense of direction and to feed into that and help shape the future of oral care.'

By Adrian O'Dowd

\section{Notice of death}

It is with sadness that we announce the death of George Bisterfeld, Export Manager of Shofu Dental, who passed away at the age of 64 .
Mr Bisterfeld joined Shofu in October 1987 and built up the export department and developed the international Shofu business. He was a substantial part of
Shofu's success in Europe over the last three decades and had close ties to dealers and opinion leaders globally in the dental industry. 